\title{
EFFECT OF PRIMARY DOPANTS ON THE CONDUCTIVITY OF POLYANILINE SYNTHESIZED BY ELECTROCHEMICAL POLYMERIZATION
}

\author{
O. A. Nunoo, Joseph Asare Awuah, Eric K. K. Abavare and K. Singh \\ Department of Physics, Kwame Nkrumah University of Science and Technology \\ Kumasi, Ghana (West Africa)
}

\begin{abstract}
Polyaniline salts were synthesized at room temperature $\left(30^{\circ} \mathrm{C}\right)$ by electrochemical oxidation using primary dopants such as $\mathrm{HCL}, \mathrm{HNO}_{3}, \mathrm{H}_{2} \mathrm{SO}_{4}$ and $\mathrm{CH}_{3} \mathrm{COOH}$. All the synthesized PANI have resulted in emeraldine salt form as indicated by dark green colour of the salts. Various characterization techniques employed were UV-Visible spectroscopy, FT-IR and Cyclic voltammetry studies. All these techniques confirm the various properties of PANI. The characteristic peaks in the UV-Visible spectra of the samples indicate that effective doping has occurred in the synthesized polymer polymers. Quinoid and benzenoid bands at 1553-1596 $\mathrm{cm}^{-1}$ and $1437-1496 \mathrm{~cm}^{-1}$ respectively were observed in all the samples. The band gaps for all the samples were obtained using the absorption spectra and Stern relation. PANI- $\mathrm{H}_{2} \mathrm{SO}_{4}$ had the least band gap whereas $\mathrm{PANI}-\mathrm{CH}_{3} \mathrm{COOH}$ had the highest band gap. The voltammograph showed the various oxidation states during the electrochemical deposition at a potential of $0.8 \mathrm{~V}$. Four probe Method was used to study the conductivity of both thin films deposited on ITO slides. The conductivity values for $\mathrm{PANI}-\mathrm{H}_{2} \mathrm{SO}_{4}$ were found to be $3.424 \mathrm{S.cm}^{-1}$ for thin film. By comparing the four samples' $\pi-\pi^{*}$ transition, from the strongest to the weakest were in the order: , PANI- $\mathrm{H}_{2} \mathrm{SO}_{4}$ followed by PANI-HCl then $\mathrm{PANI}-\mathrm{HNO}_{3}$ and the weakest been $\mathrm{PANI}-\mathrm{CH}_{3} \mathrm{COOH}$. This suggests that polaron charge carriers are responsible for the high conductivity in $\mathrm{H}_{2} \mathrm{SO}_{4}$ doped PANI.
\end{abstract}

Keywords: Conductivity, Electrochemical, Polymerization

Cite this Article: O. A. Nunoo, Joseph Asare Awuah, Eric K. K. Abavare and K. Singh, Effect of Primary Dopants on the Conductivity of Polyaniline Synthesized by Electrochemical Polymerization, International Journal of Advanced Research in Engineering and Technology (IJARET), 10 (6), 2019, pp 157-163.

$\mathrm{http}: / /$ iaeme.com/Home/issue/IJARET?Volume $=10 \& \mathrm{Issue}=6$

\section{INTRODUCTION}

Polyaniline (PANI) is one of the most studied conjugated polymers due to its widely tunable electrical conductivity (Cao et al., 1992) and environmental stability (Rannou and Nechtschein, 1997, DeLongchamp and Hammond, 2001). PANI can be readily synthesized 
from commercially available starting materials under gentle conditions by oxidation methods (Masters et al., 1991), (Wei et al., 1989). Polyaniline remains one of the most interesting materials due to its unique conduction mechanism and good environmental stability in the presence of oxygen and water vapour (Kumar et. al.,1997).

The process ability, conductivity and stability are major requirements of any polymer for technological application (Chauhan et al., 2011). Modifications of the oxidation state, dopant and polymerization conditions are means of optimizing the process ability, conductivity and stability of PANI for technological application. Researchers are interested in improving properties such as the electrical conductivity of PANI through the choice of appropriate dopants (Alesary et al., 2018). Dopants create charge carriers in a conducting polymer which is responsible for the conductivity of the conducting polymer (Atassi et al., 2008).

A study on the effects of primary dopants on the properties of Polyaniline will help in the determination of the appropriate dopant to produce suitable material for technological applications.

\section{METHODOLOGY}

$2.309 \mathrm{~g}$ of aniline was measured, and $0.05 \mathrm{ml}$ of distilled water was added to it. The solution was stirred under a magnetic stirrer for 5 minutes. A $0.05 \mathrm{ml}$ of the $1 \mathrm{M} \mathrm{HCl}$ solution was added to the aniline solution. This was stirred for 5 minutes to obtain uniform solution. The three electrodes [ITO (working), Platinum (counter) and $\mathrm{Ag} / \mathrm{AgCl}$ (reference)] were placed into the solution and connected to the potentiostat [ Fig. 1]. A voltage of $0.8 \mathrm{~V}$ was applied for deposition to be completed in 10 minutes for each sample. Cyclic voltammetry technique was selected from the interface using the EChem v2.1.12 software. The following parameters were used to perform the cyclic process. Scan rate of $100 \mathrm{mV} / \mathrm{s}$, Step width of $20 \mathrm{~ms}, 1$ cycle and rest time of 2 seconds were used. The procedure above was repeated for the other dopants. Voltamographs of $\mathrm{I} / \mathrm{mA}$ and $\mathrm{V} / \mathrm{mV}$ were obtained for each sample. The samples were dried at $60^{\circ} \mathrm{C}$ for 30 minutes

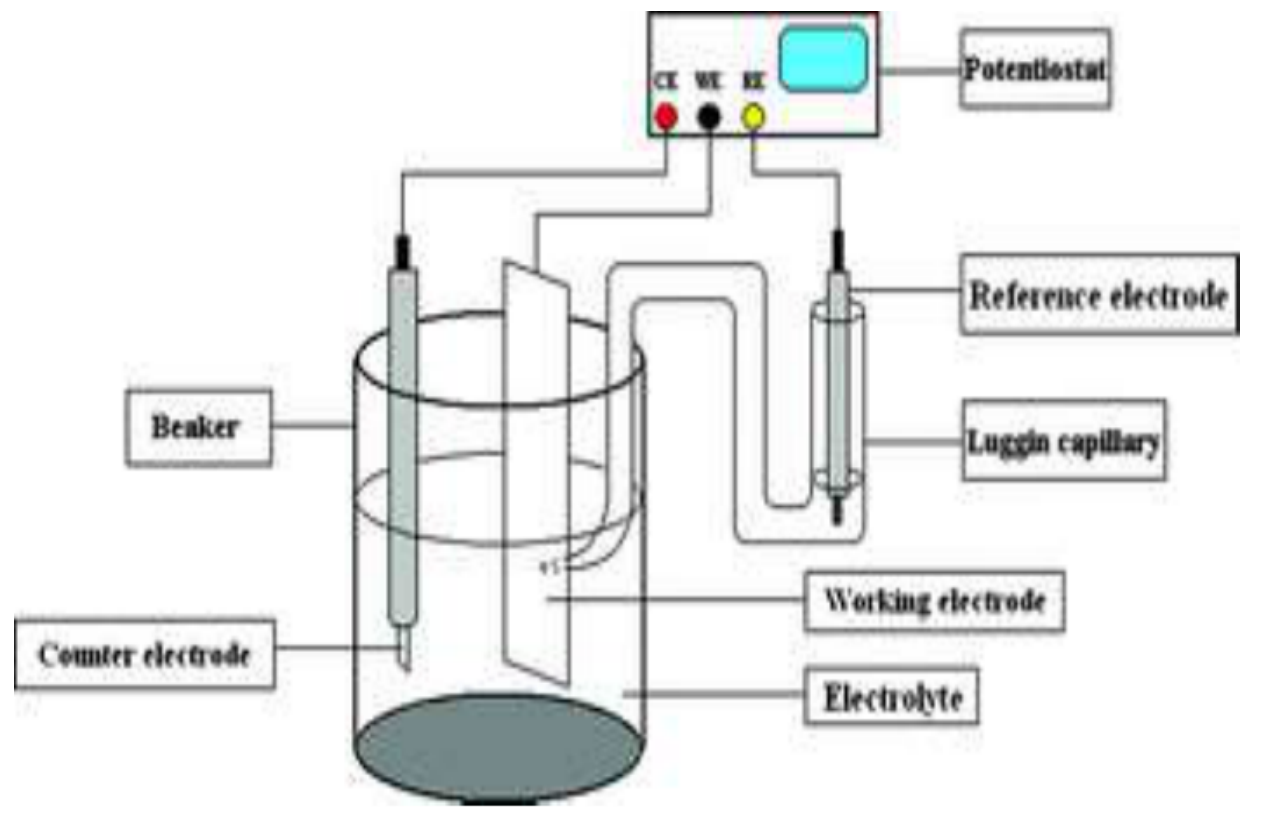

Figure 1 Electrochemical Deposition Setup 
The cell consists of the electrodes, electrolyte and power supply. Electrochemical polymerization has many advantages over chemical synthesis of PANI, such as strict control of the oxidation potential applied during synthesis providing the unique ability to moderate the polymerization initiation and termination processes (Bhadra et al., 2007). Also, there is cleanness because no extraction from the monomer-solvent-oxidant mixture is necessary, doping and thickness control via electrode potential, simultaneous synthesis and deposition of PANI thin layer. The electrochemical behavior of polyaniline is dependent on the applied potential and the surface area of the electrodes (Song et al., 2013).

Cyclic voltammetry was used to study the qualitative information about the electrochemical process in synthesizing PANI by electrodeposition on an ITO glass with aqueous acids forming part of the electrolyte. Cyclic voltammograms obtained from the electrochemical process using the eDaQ software integrated into the POTENTIOSTAT 468 device that was used for this experiment.

\section{RESULTS AND DISCUSSION}

\subsection{FTIR of Thin Films}

The most dominant bands in the entire spectra which are clear characteristics of polyaniline were $3468 \mathrm{~cm}^{-1}-3025.17 \mathrm{~cm}^{-1}, 1593 \mathrm{~cm}^{-1}-1553 \mathrm{~cm}^{-1}, 1481 \mathrm{~cm}^{-1}-1413 \mathrm{~cm}^{-1}, 1300 \mathrm{~cm}^{-1}$ $-1239 \mathrm{~cm}^{-1}, 1142 \mathrm{~cm}^{-1}-1022 \mathrm{~cm}^{-1}$ and $883 \mathrm{~cm}^{-1}-880 \mathrm{~cm}^{-1}$. Below is a table for the various peaks recorded for the thin film samples.

Table 1 Fourier Transformation Infrared Spectroscopy of the Thin Film Samples

\begin{tabular}{|l|c|c|c|c|c|c|}
\hline \multicolumn{1}{|c|}{ SAMPLE } & $\begin{array}{c}\text { N-H } \\
\text { stretching }\end{array}$ & $\begin{array}{c}\text { C-H } \\
\text { stretching }\end{array}$ & $\begin{array}{c}\text { C= N } \\
\text { stretching }\end{array}$ & $\begin{array}{c}\text { Quinoid } \\
\text { Bond }\end{array}$ & $\begin{array}{c}\text { Benzenoid } \\
\text { Bond }\end{array}$ & $\begin{array}{c}\text { C-H out } \\
\text { of plane }\end{array}$ \\
\hline $\mathrm{HCl}$ & - & - & 1670 & 1561 & 1481 & 787 \\
\hline $\mathrm{H}_{2} \mathrm{SO}_{4}$ & - & - & 1650 & 1561 & 1478 & 789 \\
\hline $\mathrm{HNO}_{3}$ & 3468 & 3266 & 1673 & 1563 & 1500 & 827 \\
\hline $\mathrm{CH}_{3} \mathrm{COOH}$ & 3384 & 3050 & - & 1553 & 1481 & 820 \\
\hline
\end{tabular}

\subsection{UV-Vis Spectra Thin Film Samples}

The absorption observed for the thin films occurs between the ranges of 320-375, 400-480 and $600-720 \mathrm{~nm}$. These wavelengths reveal the electron transition in the thin film samples. In all samples, there is first the $\pi-\pi^{*}$ electron transition which occurs earliest in the weak acids between the wavelength $320-375 \mathrm{~nm}$ and then the polaron (transitions) typical of polyaniline occurring within the range of 400-480 $\mathrm{nm}$. The electron transition between the benzenoid and quinoid rings occurs at $600-720 \mathrm{~nm}$. The transitions occurring in the polaron, benzenoid and quinoid of the thin film occur in all the samples. The clear difference is in the $\pi-\pi^{*}$ transition which for the PANI-HCl and $\mathrm{PANI}-\mathrm{H}_{2} \mathrm{SO}_{4}$ occurred at a much higher wavelength. In these films there was no shift from $<300 \mathrm{~nm}$ to $>300 \mathrm{~nm}$. According to (Melad et al.,2016) such shifts are due to the steric effect which hinders charge transfer between chains and leads to low conductivity in the material. 


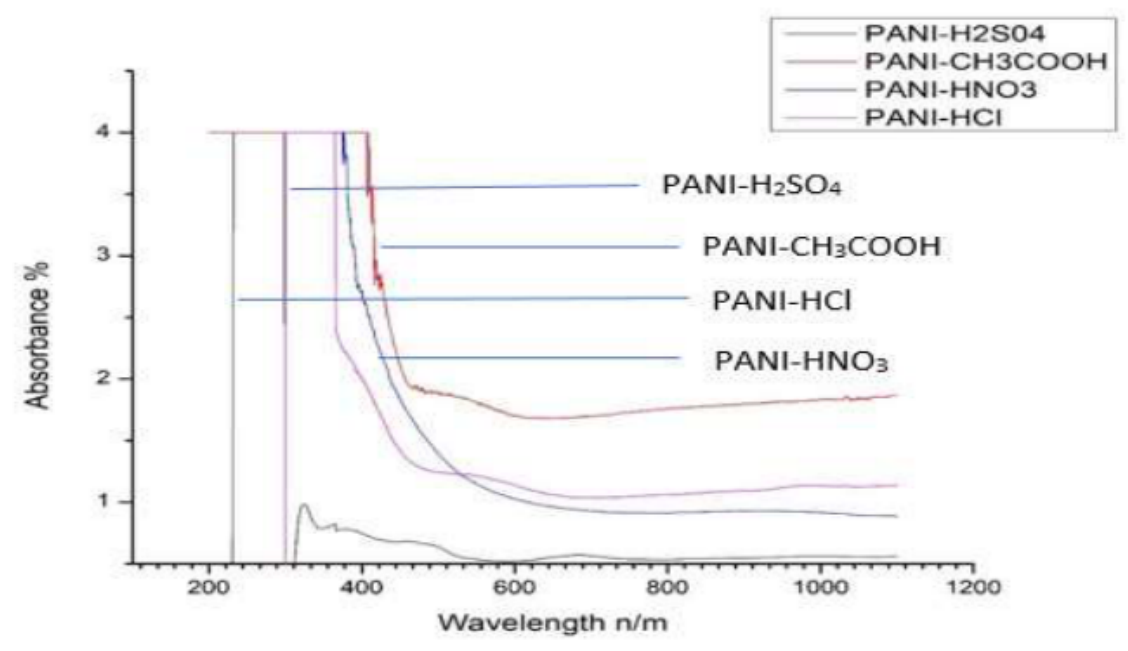

Figure 2 Absorbance versus wavelength of Thin Film samples

\subsection{Band Gap of Thin Film Samples}

The Eg obtained were $3.00 \mathrm{eV}, 2.60 \mathrm{eV}, 3.36 \mathrm{eV}$ and $4.1 \mathrm{eV}$ for PANI-HCl, PANI- $\mathrm{H}_{2} \mathrm{SO}_{4}$, $\mathrm{PANI}_{-} \mathrm{HNO}_{3}$ and $\mathrm{PANI}-\mathrm{CH}_{3} \mathrm{COOH}$ respectively.
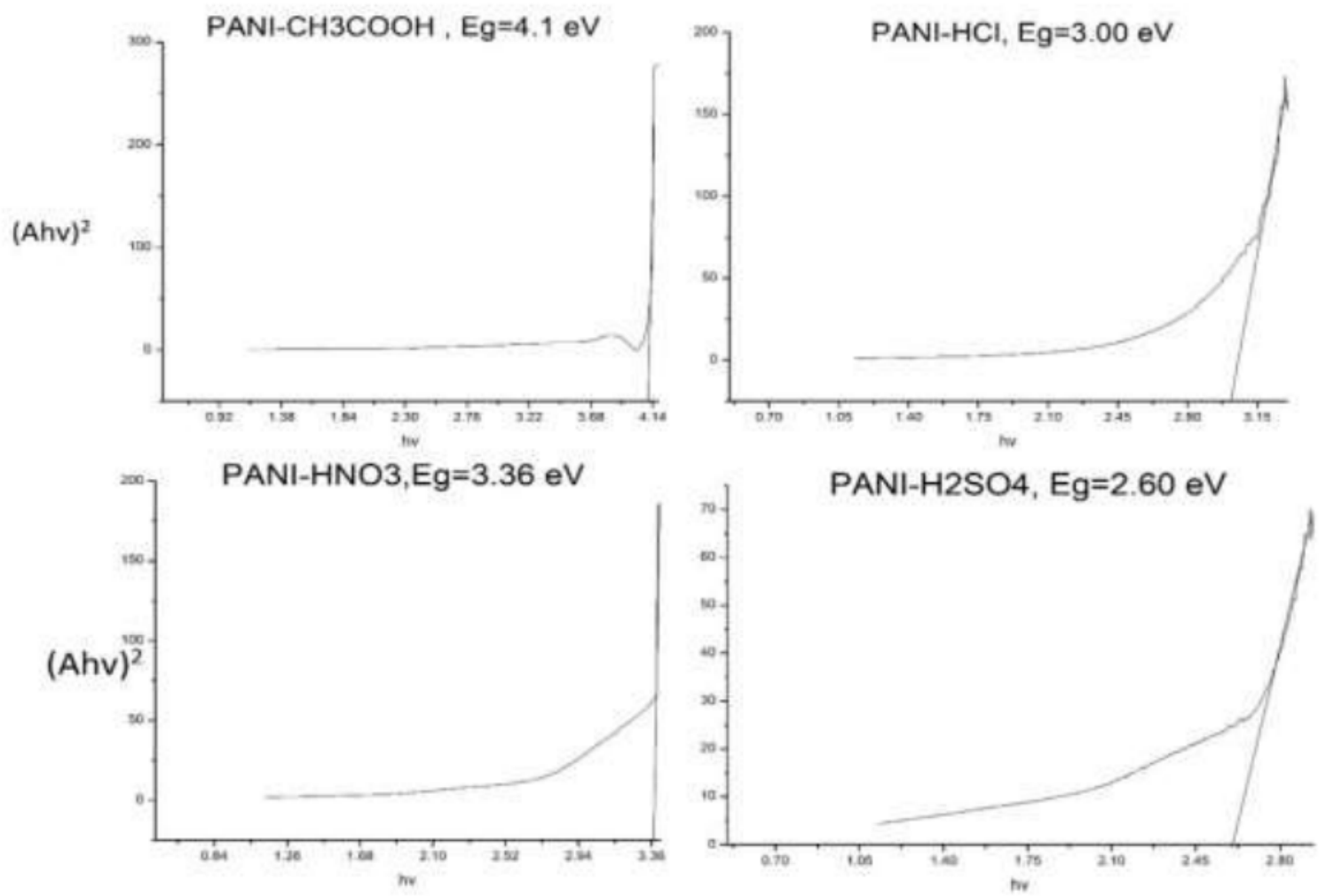

Figure 3 Band Gap of Thin film samples 


\subsection{Cyclic Voltammograms of Thin Films}
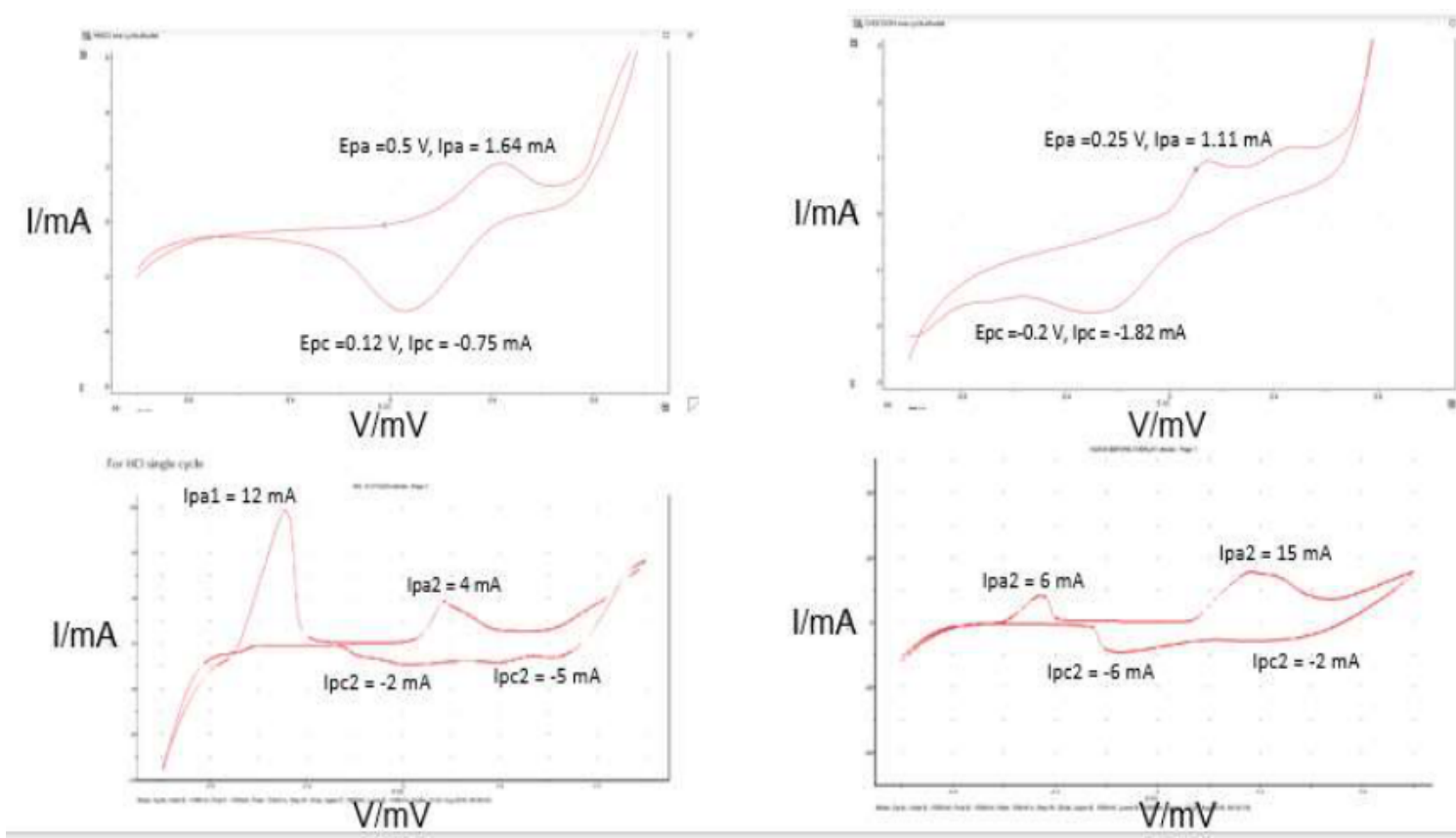

Figure 4 Voltamographs of Thin film samples

The cyclic voltammograph (CV) shows two sets of distinct redox reaction. That is two pairs of anodic and cathodic current peaks with potential peaks also. This was observed in the voltammograph for $\mathrm{HCl}$ and $\mathrm{CH}_{3} \mathrm{COOH}$. A single current peak and potential peak are observed for both cathodic and anodic processes from the voltammograph. The CV curve for $\mathrm{CH}_{3} \mathrm{COOH}$ shows a set of redox couple between the potential $\mathrm{E}=-0.29 \mathrm{~V}$ and $+0.134 \mathrm{~V}$ using the $\mathrm{Ag} / \mathrm{AgCl}$ as reference electrode. This is related to the conversion of fully reduced leucoemeraldine base to the partially oxidized emeraldine. The second set of redox couple occurs between the potentials $\mathrm{E}=+0.63 \mathrm{~V}$ and $\mathrm{E}=-0.25 \mathrm{~V}$ using $\mathrm{Ag} / \mathrm{AgCl}$ can be related to the conversion of emeraldine to the fully oxidized pernigraniline.

For all the four samples it was observed that the oxidation peak and its corresponding reduction peak appeared to move to more negative values at the scan rate used which was 100 $\mathrm{mV} / \mathrm{s}$. This implies that the protons are involved in the reaction unlike the first peaks. The anodic peak observed at more positive potentials of $\mathrm{E}=+0.13-0.73 \mathrm{~V}$ for $\mathrm{CH} 3 \mathrm{COOH}, \mathrm{E}$ $=+0.22-0.74 \mathrm{~V}$ for $\mathrm{H}_{2} \mathrm{SO}_{4}, \mathrm{E}=+0.20-0.83 \mathrm{~V}$ for $\mathrm{HCl}$ and $\mathrm{E}=+0.41-0.77 \mathrm{~V}$ for $\mathrm{HNO}_{3}$ was very strong in the first cycle of the anodic branch for the case of each electrolyte used in the experiment. This can be attributed to the initial monomer oxidation according to (Genies et al., 1987).

Almost all the monomer were oxidized between the potentials of $\mathrm{E}=+0.73$ to +0.83 V/S.C.E and afterwards a redox equilibrium was installed at $\mathrm{E}=-0.20 \mathrm{v}$ for $\mathrm{CH}_{3} \mathrm{COOH}$, $\mathrm{H}_{2} \mathrm{SO} 4$ and $\mathrm{HCl}$ except $\mathrm{HNO}_{3}$ which was installed at a potential of $\mathrm{E}=+0.06 \mathrm{~V}$. The voltammograph show a narrow anodic-cathodic peak of the polymer and according to (Genies and Lapkowski, 1987) that shows the polyaniline synthesized is highly conductive. (Bejan et al., 1998) revealed that for a $\mathrm{Pt}$ as counter electrode, reduction will always prevail and that was experienced in all the four electrolytes used in this experiment. 
O. A. Nunoo, Joseph Asare Awuah, Eric K. K. Abavare and K. Singh

Table 2 Resistivity and Conductivity of Thin Film Samples

\begin{tabular}{|l|c|c|c|c|}
\hline \multicolumn{1}{|c|}{ DOPANT } & $\begin{array}{c}\text { AVERAGE } \\
\text { CURRENT I/mA }\end{array}$ & $\begin{array}{c}\text { AVERAGE } \\
\text { VOLTAGE } \\
\text { V/mV }\end{array}$ & $\boldsymbol{\rho} / \mathbf{\Omega . c m}$ & $\boldsymbol{\sigma} / \mathbf{~ S .} \mathbf{c m}^{-1}$ \\
\hline $\mathrm{HCl}$ & 2.00 & 3.10 & 0.337 & 2.967 \\
\hline $\mathrm{H}_{2} \mathrm{SO}_{4}$ & 2.00 & 3.40 & 0.292 & 3.424 \\
\hline $\mathrm{HNO}_{3}$ & 2.00 & 8.60 & 0.994 & 1.006 \\
\hline $\mathrm{CH}_{3} \mathrm{COOH}$ & 2.00 & 14.20 & 0.998 & 1.002 \\
\hline
\end{tabular}

\section{CONCLUSION}

Polyaniline, PANI-ES was synthesized by electrochemical oxidation using four different dopants $\left(\mathrm{HCl}, \mathrm{H}_{2} \mathrm{SO}_{4}, \mathrm{HNO}_{3}\right.$ and $\left.\mathrm{CH}_{3} \mathrm{COOH}\right)$. UV-Vis spectroscopy was carried out on the samples prepared by the methods stated. Absorption peak was observed between the ranges of $300-350 \mathrm{~nm}$ which depicts the $\pi-\pi^{*}$ electron transition. Another peak between $450-540 \mathrm{~nm}$ was also noticed for in all the samples and can be attributed to the polaron and bipolaron transition in polyaniline. This observation was made in all the samples prepared by the different acids or dopants). The band gap for the thin film samples were in the range of 2.60$3.83 \mathrm{eV}$.

\section{REFERENCES}

[1] D. Bejan and A. Duca. Voltammetry of aniline with different electrodes and electrolytes. Croaticachemica acta, 71(3), 1998, pp 745-756.

[2] S. Bhadra, N. K. Singha, and D. Khastgir. Electrochemical synthesis of polyaniline and its comparison with chemically synthesized polyaniline. Journal of applied polymer science, 104(3), 2007, pp 1900-1904.

[3] Y. Cao, P. Smith, and A. J. Heeger. Counter-ion induced processibility of conducting polyaniline and of conducting polyblends of polyaniline in bulk polymers. Synthetic Metals, 48(1), 1992, pp 91-97.

[4] D. DeLongchamp and P. T. Hammond. Layer-by-layer assembly of pe- dot/polyaniline electrochromic devices. Advanced Materials, 13(19), 2001, pp 1455-1459, 2001.

[5] E. Genies and M. Lapkowski. Spectroelectrochemical evidence for an intermediate in the electropolymerization of aniline. Journal of electroanalytical chemistry and interfacial electrochemistry, 236(1-2), 1987, pp 189-197.

[6] J. Masters, Y. Sun, A. MacDiarmid, and A. Epstein. Polyaniline: allowed oxidation states. Synthetic Metals, 41(1-2), 1991, pp 715-718.

[7] M. A. Rahman, P. Kumar, D.-S. Park, and Y.-B. Shim. Electrochemical sensors based on organic conjugated polymers. Sensors, 8(1), 2008, pp 118-141.

[8] P. Rannou and M. Nechtschein. Aging studies on polyaniline: conductivity and thermal stability. Synthetic Metals, 84(1), 1997, pp 755-756.

[9] T. Sharma, S. Aggarwal, S. Kumar, V. Mittal, P. Kalsi, and V. Manchanda. Effect of gamma irradiation on the optical properties of cr-39 polymer. Journal of materials science, 42(4), 2007, pp 1127-1130. 
Effect of Primary Dopants on the Conductivity of Polyaniline Synthesized by Electrochemical Polymerization

[10] E. Song and J.-W. Choi. Conducting polyaniline nanowire and its applications in chemiresistive sensing. Nanomaterials, 3(3), 2013, pp 498-523.

[11] Y. Wei, X. Tang, Y. Sun, and W. W. Focke. A study of the mechanism of aniline polymerization. Journal of Polymer Science Part A: Polymer Chemistry, 27(7), 1989. $2385-2396$

[12] Kofi Owusu-Sekyere, Isaac Nkrumah, R. K. Nkum and K. Singh, Effect of PH on The Optical - Absorption of Polyaniline Thin Films Prepared by Electrochemical Polymerization on ITO Glass. International Journal of Advanced Research in Engineering and Technology, 7(4), 2016, pp 43-49.

[13] F. Alesary, Hani Khalil Ismail, Ahmed Fadhil Khudhair, and Mohammed Qasim Mohammed, Oriental Journal of Chemistry 2018, vol. 34, no.(5): pg. 2525-2533

[14] N. P. S. Chauhan, Rakshit Ameta, Rohit Ameta, \& Suresh C Ameta, Indian Journal of Chemical Technology, Vol. 18, March 2011, pp. 118-122.

[15] Ujvala P. Christian and Shrikant J. Wagh, Effect of Phase Volume Ratio on Synthesis of Polyurea Microcapsules by Interfacial Polymerization, International Journal of Advanced Research in Engineering and Technology, 9(3), 2018, pp 60-65.

[16] Y. Atassi, Mohammad Tally and Mazen Ismai, Synthesis and characterization of chloride doped polyaniline by bulk oxidative chemical polymerization Doping effects on electrical conductivity, manuscript, 2008. 